\title{
Visualization of Gross Anatomy for Ultrasound Scanning Planes Using a Virtual Dissection Table
}

\author{
Visualización de la Anatomía Macroscópica para Planos de \\ Escaneo de Ultrasonido Utilizando una Mesa de Disección Virtual
}

Hyo-Min Cho'; Yongho Lee $^{2}$ \& Cheolpyo Hong ${ }^{2}$

CHO, H. M.; LEE, Y. \& HONG, C. Visualization of gross anatomy for ultrasound scanning planes using a virtual dissection table. Int. J. Morphol., 39(1):7-10, 2021.

SUMMARY: There is a lack of visualization on gross anatomy planes for the non-orthogonal sections, such as subcostal and intercostal oblique scanning planes of ultrasound imaging. The aim of the present study was to visualize the anatomical image of corresponding plane for the oblique ultrasound scanning using a virtual dissection system. the oblique gross anatomy plane was constructed by appropriate segmentation using a virtual dissection table. A suitable cutting of the body plane was accomplished by turning on and off the organ systems, particularly the skeletal system, category, and structure. The right hepatic vein (RHV), middle hepatic vein (MHV), and left hepatic vein (LHV) for the right subcostal oblique plane appeared in the single slice plane. The location of the liver, gallbladder, and kidneys differently appeared in the oblique anatomical plane and body position. The results of this study suggest that using a virtual anatomy system contributes to improving the sonographer's ability to understand anatomy.

KEY WORDS: Gross anatomy planes; Virtual dissection; Ultrasound scanning plane.

\section{INTRODUCCIÓN}

Ultrasound imaging, also known as sonography or ultrasonography, employs mechanical pressure vibration to generate images of the inside of the human body (Szabo, 2004; Hoskins et al., 2010; Shung, 2015). Ultrasound imaging uses sound waves, which are typically non-ionizing radiation, noninvasive, and safe (Barnett et al., 2000; Duck, 2008). Sonography is valuable for imaging soft tissues contrast of organs and tissues (Wells \& Liang, 2011; Frulio $\&$ Trillaud, 2013). Doppler ultrasonography is another powerful tool to evaluate the blood velocity (Kremkau, 1990; McDicken et al., 1992; Cohen et al., 2001; Grant et al., 2003). Due to these characteristics, ultrasonography is widely used in cardiology, endocrinology, orthopedics, obstetrics, and gynecology (Ferrucci Jr., 1979; Kaminsky et al., 1997; Moore \& Copel, 2011; Erçikti et al., 2017).

In ultrasound imaging, scanning planes are established in the direction of the ultrasound beam lines and are determined by slightly moving the ultrasound transducer. During the ultrasound examination, the transducer can be moved to an arbitrary orientation, twisting, and rotating. Typically used ultrasound scan planes include the transverse plane, longitudinal plane, subcostal oblique plane, and intercostal oblique plane (Fukuda, 1996; Mattoon et al., 2014). Most gross anatomy information is provided with three standard orthogonal sections-namely, sagittal, coronal, and transverse planes.Transverse and longitudinal planes are easily recognized by the three standard planes.

However, there is a lack of visualization on gross anatomy planes for the subcostal and intercostal oblique scanning planes of ultrasound imaging.For instance, while the left, middle, and right hepatic vein branches can be routinely visualized using the right subcostal oblique scanning, such an image is not provided in gross anatomy planes. Physicians and technicians using ultrasound imaging system should only predict oblique imaging plane information through a formalized gross anatomy. The virtual dissection system based on the anatomy digital images allows a user to cutthe virtual body in any direction (Chung et al., 2015). Furthermore, an appropriate cutting of the section is accomplished by using the human organ systems category of the virtual dissection system. In the present study, we visualized the anatomical image of corresponding plane for the oblique ultrasound scanning using a virtual dissection system. 


\section{MATERIAL AND METHOD}

Virtual dissection system. Virtual dissection table produced by Anatomage company (San Jose, CA, United States) was used to generate the gross anatomy plane for imaging plane (Fig. 1a.). The Anatomage virtual dissection table was a segmented 3D whole-body anatomy system providing various arbitrary planes and three orthogonal sections. Digitized images of human anatomy were presented in an interactive manner on a life-sized touch screen. The oblique and specialized gross anatomy planes were constructed by appropriate segmentation. A suitable cutting of the body plane was accomplished by turning on and off the organ systems, particularly the skeletal system, category, and structure (Fig. 1b). The vascular and digestive system also was used to appropriate cut the plane.

Oblique anatomical images planes. The right costal margin of the rib cage was designated by a skeletal model on the Anatomage table. The right subcostal oblique sectionsalong the oblique costal margin were selected from the left superior to the right inferior direction (Fig. 2). Various section images were generated along the oblique planes, including the intravenous branches in the liver. The optimal cross section was selected by the most similar image plane to the right subcostal oblique scanning of sonography. The right extended intercostal oblique planes were selected from the right superior to the left inferior directions (Fig. 3). The appropriate cross section was chosen by the most similar image plane to the right extended intercostal oblique scanning of sonography. This cross section was selected by including the liver, gallbladder, and kidneys. The oblique plane on prone position was selected from the right superior to the left inferior direction (Fig. 4). The suitable oblique plane was chosen by the most similar sonography scanning image for the consideration of the liver and kidney location. Selected planes were obtained through repeated cutting.

\section{RESULTS}

The branches of hepatic veins were visualized as the corresponding anatomical images for the right subcostal oblique plane (Fig. 2c). The right hepatic vein (RHV), middle hepatic vein (MHV), and left hepatic vein (LHV) were displayed on one section image. These veins appeared in the bottom right portion of the liver region in a sonographylike view. Figure $3 \mathrm{c}$ shows the anatomical image of the corresponding plane for the right extended intercostal oblique

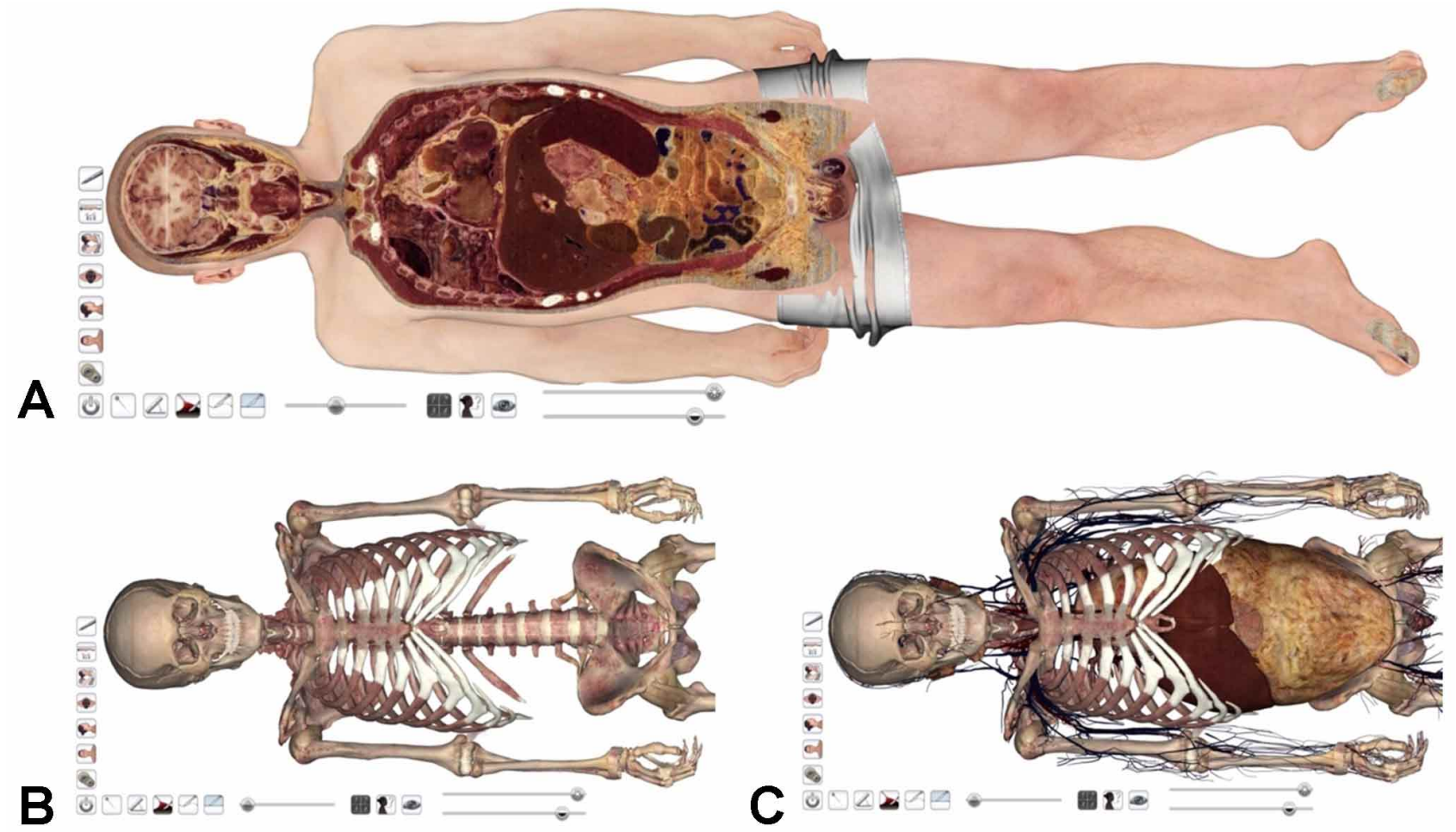

Fig. 1. The Anatomage virtual dissection table images. Life-size dissection image of human anatomy on the coronal plane (a). The skeletal system (b) and composite images of the skeletal, vascular, and digestive systems (c). 
sonography scanning. The gallbladder appeared in a higher upper part than the kidney in a sonography-like view. The liver part was displayed on the right side of the sonographylike view. Figures 2 and 3 were acquired on the virtual body supine position. The kidney appeared in a higher upper part than the liver in the prone position in a sonography-like view (Fig. 4c). The organs were differently displayed along the cutting oblique plane and body position.
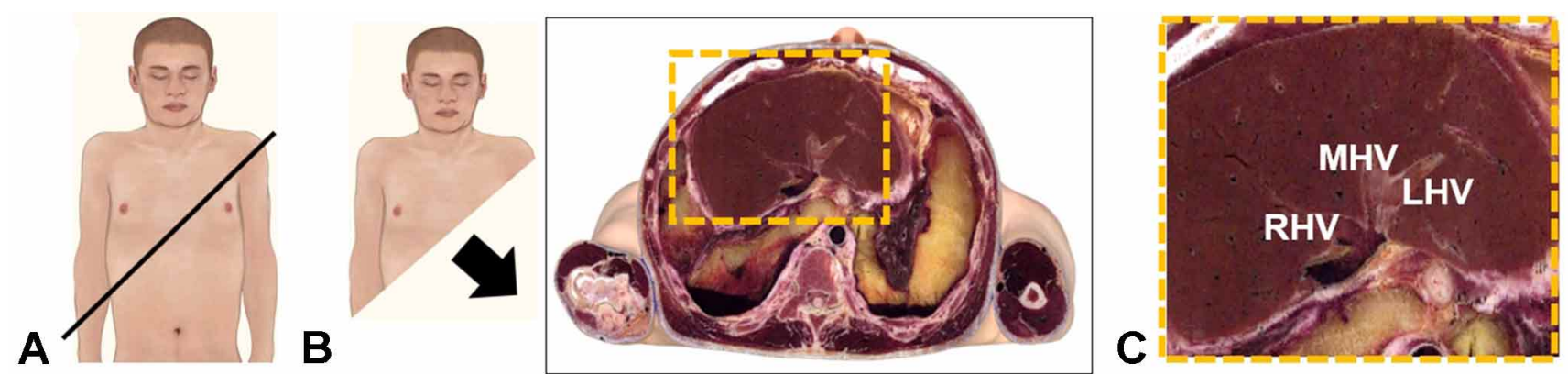

Fig. 2. The anatomical image of the corresponding plane for the right subcostal oblique scanning of sonography. The virtual anatomical images (a) and the corresponding plane images (b and c). (The black line; cutting line, the yellow box: a sonography-like view, the right hepatic vein, RHV; the middle hepatic vein, MHV; and the left hepatic vein, LHV).
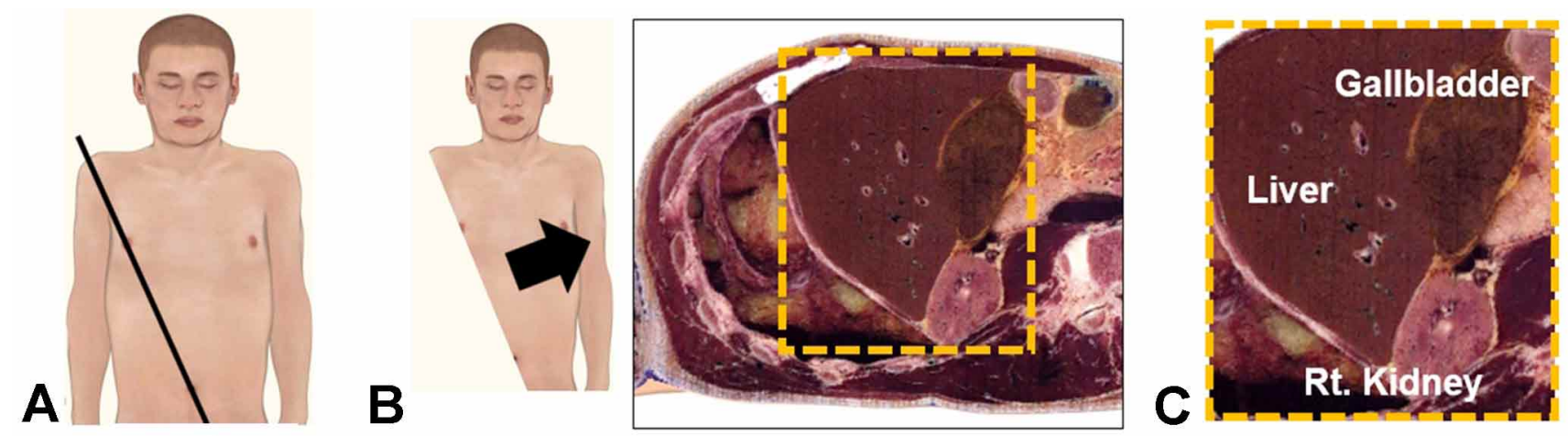

Fig. 3. The anatomical image of the corresponding plane for the right extended intercostal oblique scanning of sonography. The virtual anatomical images (a) and the corresponding plane images ( $b$ and c). The liver, gallbladder, and kidneys are represented in the identical section, and the liver is shown above the kidney on the sonography-like view. (The black line; cutting line, the yellow box: a sonographylike view).

\section{A}
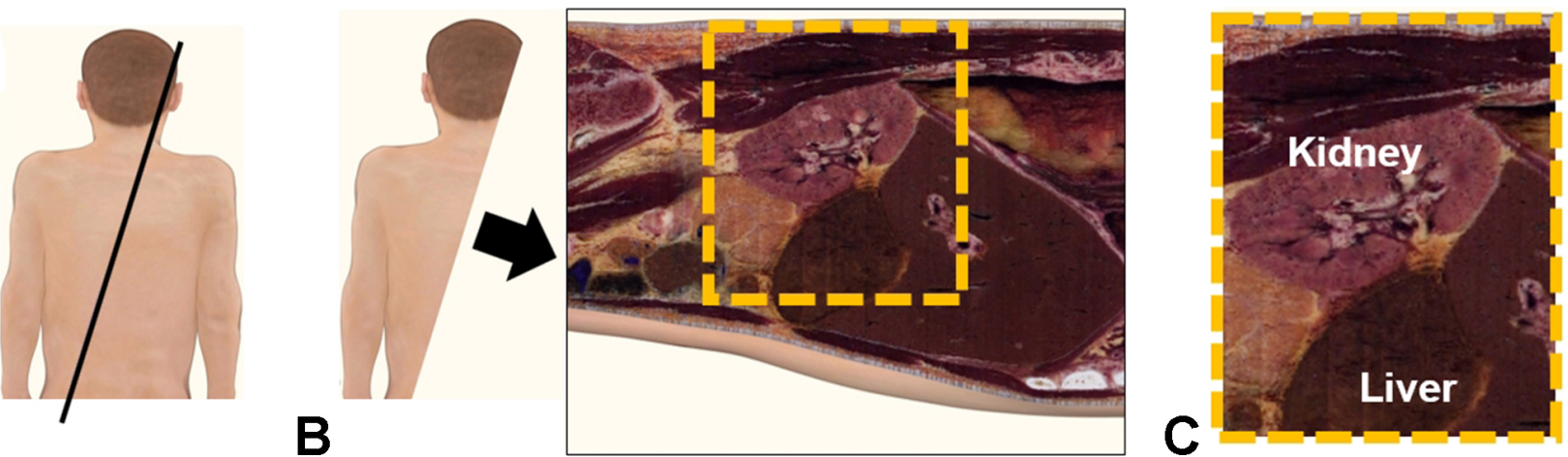

Fig. 4. The anatomical image of the corresponding plane for the oblique scanning on prone position of sonography. The virtual anatomical images (a) and the corresponding plane images ( $\mathrm{b}$ and c). The liver and the right kidney are represented in the identical section, and the kidney is shown above the liver on the sonography-like view. (The black line; cutting line, the yellow box: a sonography-like view). 


\section{DISCUSSION}

In this study, we visualized the oblique anatomical plane for the corresponding sonography-like image using a virtual dissection system. The RHV, MHV, and LHV appeared in single slice plane (Fig. 2c). This image is similar to the one obtained from the upper abdominal ultrasound scan. Such an image was not provided in gross anatomy images.Ultrasound probes are placed on the skin surface. The upper part of sonographic image is a superficial region, while the lower part is a deep region of the body position. In addition, the acquired ultrasound image varies depending on the position of the patient in which the probe is placed. The liver appeared in a higher upper part than the kidney on the supine position in the upper abdominal ultrasound scan (Fig. 3c). Conversely, the kidney was represented in a higher upper part than the liver in the patient prone position (Fig. 4c). In addition, the sonography image has the limited scan field-of-view (FOV). The characteristics of sonographic images mentioned above can be easily expressed by using the virtual anatomy dissection system.

Ultrasound imaging is affected by the patient's breathing, movement, and probe handling status. Although the oblique plane extracted in the present study may not exactly match ultrasonic imaging anatomy, the virtual anatomy system helps to better understand cross-sectional image anatomy. Furthermore, the quality of ultrasound images heavily depends on the operator. For an accurate diagnosis, operators should have a comprehensive understanding of oblique anatomy sections. Consequently, the use of a virtual anatomy system contributes to improving the sonographer's ability for diagnosis.

CHO, H. M.; LEE, Y. \& HONG, C. Visualización de la anatomía macroscópica para planos de escaneo de ultrasonido utilizando una mesa de disección virtual. Int. J. Morphol., 39(1):7-10, 2021.

RESUMEN: Existe una falta de visualización en los planos de anatomía macroscópica para las secciones no ortogonales, tal como los planos de exploración oblicuos subcostales e intercostales en las imágenes de ultrasonido. El objetivo del presente estudio fue visualizar la imagen anatómica del plano correspondiente para la ecografía oblicua mediante un sistema de disección virtual. El plano de anatomía macroscópica oblicua se construyó mediante una adecuada segmentación utilizando una mesa de disección virtual. Se logró un corte correcto del plano corporal al encender y apagar los sistemas de órganos, particularmente el sistema esquelético, la categoría y la estructura. La vena hepática derecha, la vena hepática media y la vena hepática izquierda para el plano oblicuo subcostal derecho aparecieron en el plano de corte único. La ubicación del hígado, la vesícula biliar y los riñones aparecieron de manera diferente en el plano anatómico oblicuo y en la posición del cuerpo. Los resultados de este estudio sugieren que el uso de un sistema de anatomía virtual ayuda a mejorar la capacidad del ecografista para comprender la anatomía humana.

PALABRAS CLAVE: Planos de anatomía macroscópica; Disección virtual; Plano de exploración por ultrasonido.

\section{REFERENCES}

Barnett, S. B.; Ter Haar, G. R.; Ziskin, M. C.; Rott, H. D.; Duck, F. A. \& Maeda, K. International recommendations and guidelines for the safe use of diagnostic ultrasound in medicine. Ultrasound Med. Biol., 26(3):355-66, 2000.

Chung, B. S.; Shin, D. S.; Brown, P.; Choi, J. \& Chung, M. S. Virtual dissection table including the visible korean images, complemented by free software of the same data. Int. J. Morphol., 33(2):440-5, 2015.

Cohen, L. S.; Escobar, P. F.; Scharm, C.; Glimco, B. \& Fishman, D. A. Threedimensional power doppler ultrasound improves the diagnostic accuracy for ovarian cancer prediction. Gynecol. Oncol., 82(1):40-8, 2001.

Duck, F. A. Hazards, risks and safety of diagnostic ultrasound. Med. Eng. Phys., 30(10):1338-48, 2008.

Erçikti, N.; Acer, N.; Apaydi, N.; Güven, I. \& Zararsiz, G. Which method is gold standard for determination of thyroid volume? Int. J. Morphol., 35(2):452-8, 2017.

Ferrucci Jr., J. T. Body ultrasonography (first of two parts). N. Engl. J. Med., 300(10):538-42, 1979.

Frulio, N. \& Trillaud, H. Ultrasound elastography in liver. Diagn. Interv. Imaging, 94(5):515-34, 2013.

Fukuda, M. Ultrasonography of the Liver Anatomy, Procedure, Normal and Abnormal Findings in Diseased States. In: Fukuda, M.; Bergmann, H.; Padhy, A. K. \& Fukuhisa, K. (Eds.). Ultrasound and Radionuclide Images of Liver An IAEA (CRP) Group Study. Mumbai, Himalaya Publishing House, 1996.

Grant, E. G.; Benson, C. B.; Moneta, G. L.; Alexandrov, A. V.; Baker, J. D.; Bluth, E. I.; Carroll, B. A.; Eliasziw, M.; Gocke, J.; Hertzberg, B. S.; et al. Carotid artery stenosis: gray-scale and Doppler US diagnosis--Society of Radiologists in Ultrasound Consensus Conference. Radiology, 229(2):340-6, 2003.

Hoskins, P. R.; Martin, K. \& Thrush, A. Diagnostic Ultrasound: Physics and Equipment. Cambridge, Cambridge University Press, 2010.

Kaminsky, S.; Griffin, L.; Milsap, J. \& Page, D. Is ultrasonography a reliable way to confirm the diagnosis of Morton's neuroma? Orthopedics, 20(1):37-9, 1997.

Kremkau, F. W. Doppler Ultrasound: Principles and Instruments. Chicago, Saunders, 1990.

Mattoon, J. S.; Berry, C. R. \& Nyland, T. G. Abdominal Ultrasound Scanning Techniques. Small Animal Diagnostic Ultrasound. 3rd ed. St Louis, Elsevier Saunders, 2014. pp.94-127.

McDicken, W. N.; Sutherland, G. R.; Moran, C. M. \& Gordon, L. N. Colour doppler velocity imaging of the myocardium. Ultrasound Med. Biol., 18(6-7):651-4, 1992.

Moore, C. L. \& Copel, J. A. Point-of-care ultrasonography. N. Engl. J. Med., 364:749-57, 2011.

Shung, K. K. Diagnostic Ultrasound: Imaging and Blood Flow Measurements. 2nd ed. London, CRC Press, 2015.

Szabo, T. L. Diagnostic Ultrasound Imaging: Inside Out. New York, Academic Press, 2004.

Wells, P. N. T. \& Liang, H. D. Medical ultrasound: imaging of soft tissue strain and elasticity. J. R. Soc. Interface, 8(64):1521-49, 2011.

Corresponding author:

Cheolpyo Hong, PhD

Assistant Professor

Department of Radiological Science

Catholic University of Daegu

Hayang-ro 13-13, Hayang-eup

Gyeongsan-si

Gyeongbuk, 38430

REPUBLIC OF KOREA

Email: chong@cu.ac.kr 